\title{
Design, construction and evaluation of an energy harvesting prototype built with piezoelectric materials
}

\author{
Diseño, construcción y evaluación de un prototipo de cosechamiento de energía construido \\ con materiales piezoeléctricos
}

\section{Alejandra Echeverry-Velásquez (D) ${ }^{1 *}$, Mateo Vélez-Quintana (D) 1, José Alejandro Posada-Montoya (D) 1, José-Alfredo Palacio-Fernández (iD ${ }^{3}$ \\ 1Semillero de Investigación Ambiental SIA, Grupo de Investigación e Innovación Ambiental, Facultad de Ingeniería, Institución Universitaria Pascual Bravo. Calle 73 \# 73A - 226. C. P. 050034. Medellín, Colombia.}

\section{CITE THIS ARTICLE AS:}

\author{
A. Echeverry, M. Vélez, J. A. \\ Posada and J. A. Palacio. \\ "Design, Construction and \\ Evaluation of an Energy \\ Harvesting Prototype built with \\ Piezoelectric Materials", \\ Revista Facultad de Ingeniería \\ Universidad de Antioquia, no. \\ 97, pp. 56-64, Oct-Dec 2020. \\ [Online]. Available: https: \\ //www.doi.org/10.17533/ \\ udea.redin. 20200161
}

\section{ARTICLE INFO:}

Received: May 29, 2019

Accepted: January 24, 2020

Available online: January 24, 2020

\section{KEYWORDS:}

Renewable energy; cantilever beam; resonance frequency; ultracapacitors

Energía renovable; viga en voladizo; frecuencia de resonancia; ultracapacitores
ABSTRACT: The piezoelectricity allows the generation of electric power taking advantage of the movement of vehicles and pedestrians. Many prototypes have been made with piezoelectric generators, but at present, their commercialization and use have not been popularized due to their low power generation and energy losses. A design of an experimental prototype of an energy harvester with piezoelectric materials that reduces these losses and generates more energy thanks to the resonance with the beams is proposed in this article. An equilateral triangular tile is designed such it will not deform when a force acts on it. The tile has four-cantilever beams, and it is designed to resonate with the natural frequency of the piezoelectric material. This is coupled to the piezoelectric device. The vibration generated on the beam, by a mechanical load, is used to generate more energy when it resonates. The piezoelectric is a ceramic material and generates a nominal power of $75 \mathrm{~mW}$ before placing it on the beam, and $375 \mathrm{~mW}$ after being placed on the beam. However, the energy collection circuit has losses due to its own consumption, the transmission of energy to the storage system, and in the mechanical system.

RESUMEN: La piezoelectricidad permite la generación de energía eléctrica aprovechando el movimiento de vehículos y peatones. Se han realizado muchos prototipos con generadores piezoeléctricos, pero en la actualidad no se ha popularizado su comercialización y utilización. Se presenta en este artículo un diseño de un prototipo experimental de un cosechador de energía con materiales piezoeléctricos. Con el aprovechamiento de la energía peatonal se realiza el diseño de una baldosa para la implementación en espacios interiores. En esta propuesta se realizó el diseño previo de la baldosa que es de tipo triangular equilátera, para que no se deforme cuando actúe una fuerza sobre ella. Está conformado por un sistema de cuatro vigas en voladizo, diseñadas con el objetivo de que entren en resonancia y se pueda aumentar la energía obtenida del material piezoeléctrico. La vibración generada sobre la viga, por medio de una carga mecánica es aprovechada para generar energía. Los piezoeléctricos son de material cerámico. Antes de colocarlo en la viga, se generó $75 \mathrm{~mW}$ nominales, y con la viga generó una potencia de $375 \mathrm{~mW}$. Sin embargo, el circuito de recolección de la energía tiene pérdidas debido a su propio consumo, a la transmisión de la energía al sistema de almacenamiento y en el sistema mecánico.

\section{Introduction}

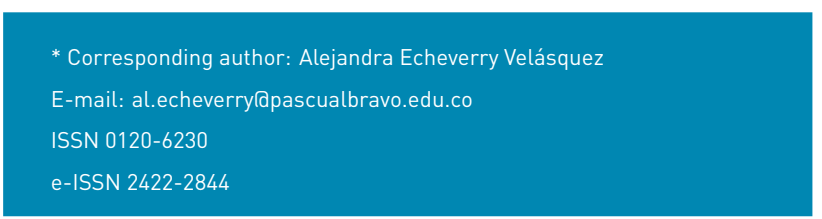

Global temperature has increased $1^{\circ} \mathrm{C}$ from the pre-industrial stage. Due to this climate change, sea level is increasing, arctic permafrost is thawing, extreme meteorological events are being observed, among other factors. All of them leading to the deterioration of the 
planet while causing incalculable economic and human losses [1]. In 2030, the temperature is estimated to rise to $1.5^{\circ} \mathrm{C}$, bringing even more serious consequences. If the temperature increases by $2^{\circ} \mathrm{C}$, it is estimated that more than $25 \%$ of the species will disappear [2]. One of the economic sectors that contributes most Green House Gases (GHG) into the atmosphere is electricity and heat production [3]. Currently, the dependence on fossil fuels for power generation leads to an environmental crisis, which is reflected in the quality of life [4]. It is necessary that renewable energies be implemented and integrated into daily life [4]. Accordingly, power generation with piezoelectricity is a friendly technology, being a viable alternative [5]. It works with vibration produced by a force. This force must be variable over time for a generation of constant power [5]. The objective of this project is to design, build, and test a prototype to generate electricity based on the movement of pedestrians using piezoelectric materials, an energy that today is unexploited. The optimum generation of piezoelectric energy is when the device operates at its resonant frequency. Therefore, the optimal energy collectors for piezoelectric devices are vibratory. Usually, the energy harvester devices appear as a cantilever beam, because they can generate a continuous load on the piezoelectric surface [6]. Different prototypes of cantilever beams with piezoelectrics have been made and sold to provide power systems in multiple applications. The best known are the load of mobile devices, LED lighting systems, lighting signs, digital signage, and Wi-fi [7]. Some researchers have focused on the optimization of electromechanical structures, and adaptation of circuits of power management, with the aim of offering the highest efficiency. Also, they have accomplished experiments on the natural frequency of a piezoelectric energy harvesting (PEH) cantilevered beam with different excitation levels. The experimental study is complemented by an analytical formulation to examine the levels of deformation, allowing to study fatigue in beams of piezoelectric energy harvester [8]. To improve the energy harvesting efficiency of a piezoelectric PZT on a cantilever beam in speed reducers, some authors used a high-performance DC-DC converter to match the impedance of the piezo [9]. Additionally, a piezoelectric material layer has been embedded in a touch screen to extrapolate the position of the localized area and since a greater pressure produces a greater voltage, the device can detect the level of force [10]. [11] developed a figure of merit analysis for key devices to contrast lead-containing and lead-free piezoceramics. [12] showed that the trimethylchloromethyl ammonium trichloromanganese(II), an organic-inorganic perovskite ferroelectric crystal processed from aqueous solution, has a large $d_{33}$ of 185 picocoulombs per newton and a high phase-transition temperature of $406 \mathrm{~K}$. [13] reviewed the progress in the field of piezoelectric biosensors, both the traditional inmunosensing and the combination with detection of nucleic acids. [14] fabricated, tested and compared three sensors using piezoresistive materials against a commercial sensor. [15] designed a piezoelectric device of low resonance frequency for the capture of electrical energy. In this article, an analysis of the energy produced by the steps of pedestrians and harvested by a piezoelectric attached to a cantilever beam is performed. Also, the amount of energy obtained by pedestrians, the design of the beam, and the design of a circuit for energy transmission and storage will be shown.

This paper is organized in various sections: Materials and methods, governing equations, analysis and results, and conclusions. In the materials and methods section, the authors present the piezoelectric used in the experiments, as well as the design of the cantilever beam used to increase the vibration, the circuit for storing the energy produced by the piezoelectric, and the design of the tile where the cantilever beam and the piezoelectric were installed. In the governing equations section, the equations for the potential energy generated by the piezoelectric, the voltage generated, the field strength, the mechanical deformation, the electrical energy, and the cantilever beam analysis are presented. In the analysis and results section, the results of the simulations of the cantilever beam's vibration, displacement, and stress are presented and discussed. Also, the power generated by a pedestrian and its storage. Finally, some conclusions are presented.

\section{Materials and methods}

\subsection{Piezoelectric}

The piezoelectric used for testing is reference 7BB-41-2C [16], made from Lead Zirconate Titanate (PZT) by Murata electronics. Its geometry is cylindrical (Figure 1), and its characteristics and dimensions are presented in Table 1. The parameters considered in the design of energy harvester are the piezoelectric material, volume, and diameter; the effective area of action for the piezoelectric, the charge level; the constant elasticity, force exerted on the piezoelectric coupling coefficient of piezoelectric, and average weight of the pedestrians.

\subsection{Design of the cantilever beam}

The prototype was designed in Autocad and consists of a wood module to support the beam (Figure 2). To demonstrate how the cantilever beam works, the authors used a beam made of saw blade Nicholson NF 1224R bimetallic steel [17].

The cantilever beam is used to increase the voltage 
Table 1 Dimensions and characteristics of piezoelectric [16]

\begin{tabular}{lllllll}
\hline $\begin{array}{l}\text { Frequency } \\
\text { resonance } \\
(\mathrm{kHz})\end{array}$ & $\begin{array}{l}\text { Plate size } \\
\text { "D" (mm) }\end{array}$ & $\begin{array}{l}\text { Diameter } \\
\text { ceramic } \\
\text { element "a" } \\
(\mathbf{m m})\end{array}$ & $\begin{array}{l}\text { Electrode } \\
\text { diameter "b" } \\
(\mathbf{m m})\end{array}$ & $\begin{array}{l}\text { Thickness } \\
\text { "T" }(\mathbf{m m})\end{array}$ & $\begin{array}{l}\text { Plate } \\
\text { thickness } \\
\text { "t" }(\mathbf{m m})\end{array}$ & $\begin{array}{l}\text { Plate } \\
\text { material }\end{array}$ \\
\hline $2.2 \pm 0.3$ & 41 & 25 & 23 & 0.63 & 0.40 & Brass \\
\hline
\end{tabular}
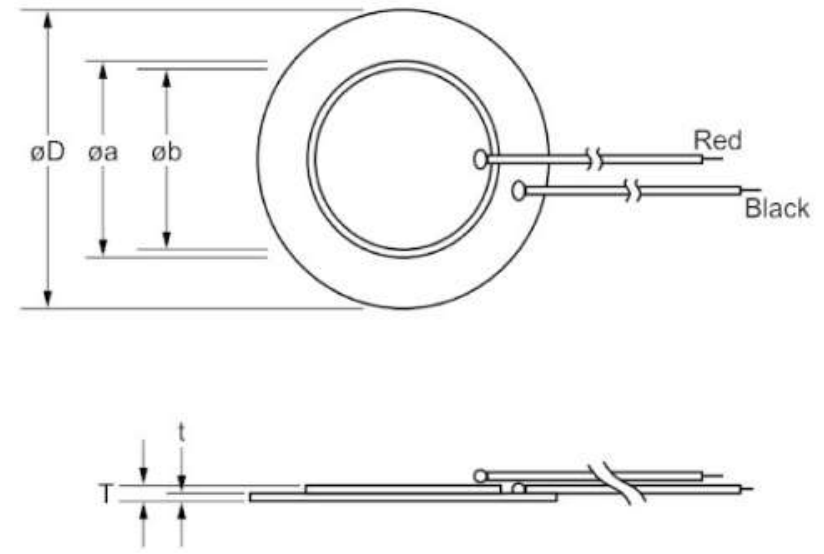

Figure 1 Murata piezoelectric illustration [16]

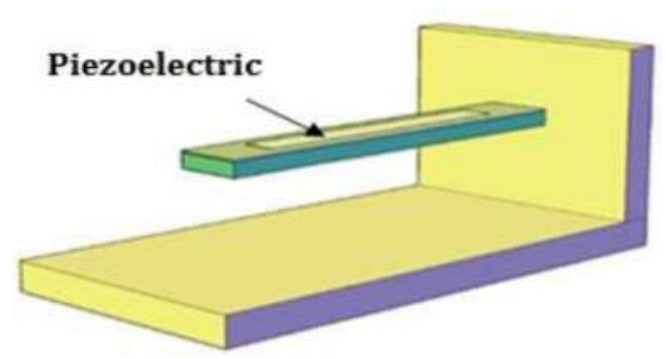

Figure 2 Module designed to simulate the behavior of the piezo

generated by the piezoelectric material. This increase is achieved by having a resonant frequency response type of the piezoelectric material and the cantilever beam [9]. To accomplish this, both frequencies (mechanical and electrical) must synchronize in the same range of natural frequencies. Therefore, the natural frequency of the cantilever beam should be within the range of the piezoelectric resonant frequency.

The natural frequencies of a cantilever beam can be calculated from the moment of inertia of the beam and the modes of flexural vibration $\lambda_{i}$. These mode shapes are a pattern that describes the shape of deflection in the beam when it is isolated from the rest of the structure. This parameter is crucial for calculating the natural frequency [18]. These mode shapes are expressed in Table 2.

A beam of rectangular cross section (Figure 3) has three natural frequencies. The resonance frequency of the piezoelectric is $2.2 \mathrm{kHz}$, with a tolerance of \pm 0.3 $\mathrm{kHz}$. To find the desired cross section with the three natural frequencies, trial and error is used to test values of $\lambda_{i}$ (non-dimensional parameter used to obtain the natural frequency in each vibration model in the boundary condition No. 3 (i.e., a cantilever beam subjected to free vibration) from Table 2 [18].

Table 2 Values for $\lambda_{i}$ (non-dimensional parameter used to obtain the natural frequency in each vibration mode) in the boundary condition No. 3 (i.e., a cantilever beam subjected to free vibration) [18]

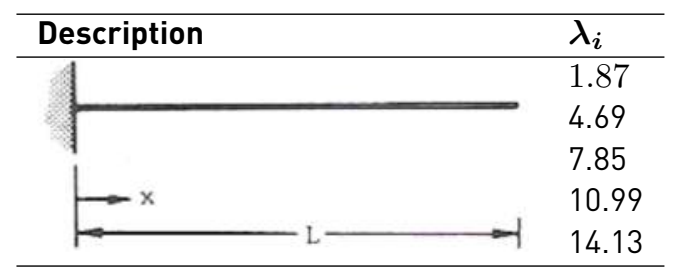

It is necessary to select the optimum material for the construction of the cantilever beam. The beam and the piezoelectric should have similar frequencies in order to resonate. The characteristics of the beam material such as Young's modulus and density should be considered. The materials evaluated for the beam are gray cast iron, aluminum, and steel. Table 3 shows the properties of these materials.

Table 3 Mechanical properties of the materials evaluated for the cantilever beam [18]

\begin{tabular}{lll}
\hline Material & $\begin{array}{l}\text { Young's } \\
\text { modulus } \boldsymbol{E} \\
\text { (GPa) }\end{array}$ & $\begin{array}{l}\text { Density } \boldsymbol{\rho} \\
\left(\frac{\boldsymbol{k g}}{\boldsymbol{m}^{\mathbf{3}}}\right)\end{array}$ \\
\hline Steel & 210 & 7850 \\
Aluminum & 70 & 2700 \\
Gray cast iron & 97 & 7870 \\
\hline
\end{tabular}

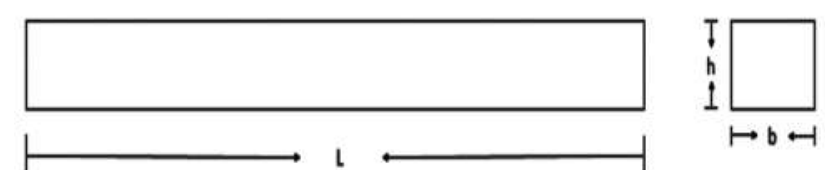

Figure 3 Geometrical characteristics of the cantilever beam

The dimensions of the beam are obtained by iterations 
until a resonant frequency like the one of the piezoelectric is obtained. The initial values of the iterations are the dimensions of the piezoelectric, which are: $0.041 \mathrm{~m}$ long, and $0.041 \mathrm{~m}$ wide. The dimensions in the following iterations will be found by simulating the previous dimension in the software: Inventor.

\subsection{Circuit for storing energy}

A temporary circuit for storing energy is built by a full wave rectifier bridge (WTE reference $2 \mathrm{~W} 10$ ), a capacitor to improve the charging process and the rectified signal, another capacitor for energy storage (from 50 to 22,000 uF electrolytic aluminum generic brand), and a voltage regulator LM 7805 [19]. The measurements were obtained on the oscilloscope GWINSTEK GDS series 2000a [20].

\subsection{Tile design}

The tile is made of triangular geometry, so as not to deform when a force acts on its surface. It has three springs below its vertices, which returns the tile to its original position through a damped oscillation [9], in this way it will allow to contain the mechanical energy and bring the tile to its initial state without suffering permanent deformation as shown in Figure 4 . These springs are kept aligned by three rails. The springs move four guides vertically applying a mechanical tensile and compression stress to four cantilever beams. Each beam has a piezoelectric generator, each of which generates a voltage in response to a mechanical load.

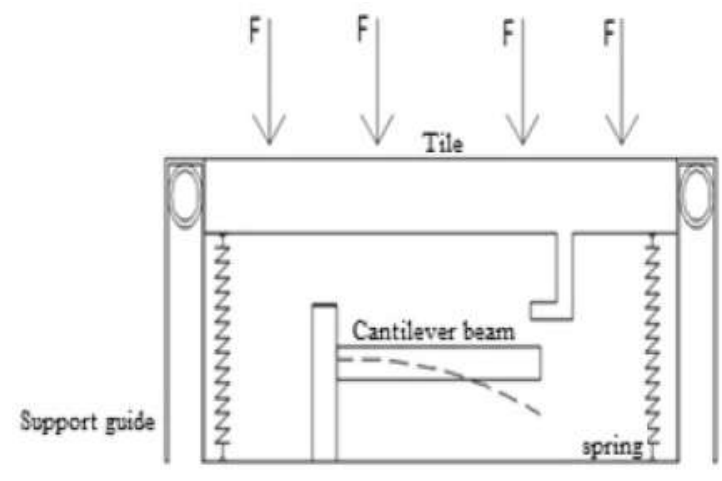

Figure 4 Design of the tile (front view)

\section{Governing equations}

\subsection{Analysis of piezoelectric}

Initially, the potential energy $E p$ generated in each step is calculated by Equation 1.

$$
E p=b . w \cdot P g h
$$

Where $E p$ is given in Joules (J) [7], $P$ is the weight given in $\mathrm{kg}, g$ is the gravity, $h$ is the height that the tile surface is moved per step (around $0.0005 \mathrm{~m}$ ), b.w. is the number of times the weight of the body is applied. The maximum amplitude of the vertical reaction force when walking is 1.0 to $1.5 \mathrm{~b} . \mathrm{w}$. (body weight) and running approximately about 2.0 to 2.9 b.w. respectively [21]. While, the average weight of a person in Colombia is around $70 \mathrm{~kg}$.

\subsection{Voltage generated}

The voltage generated by the piezoelectric is given by Equation 2.

$$
V=-\left(g_{33} h \frac{F}{A}\right)
$$

Where $V$ is the generated voltage, $g_{33}$ the piezoelectric constant, $h$ thickness or piezo length, $F$ is the force exerted on the piezoelectric, and $A$ is the area of the piezoelectric. The force exerted on this area of the piezo is also called level piezoelectric stress. It considers the geometry of the piezoelectric [22]. A negative sign means the voltage is out of phase with the load.

\subsection{Field strength}

The field strength $E$ is given in $\mathrm{V} / \mathrm{mm}$ and is given by Equation 3.

$$
E=-g_{33} T
$$

where $g_{33}$ is the piezoelectric constant, $T$ is the applied strain [23].

\subsection{Mechanical deformation}

The mechanical deformation energy is a result of the mechanical strain $T$ introduced into the piezoceramic. The mechanical strain $T$ is the quotient of force and area and the elastic constant $S_{33}$ [22] is given by Equation 4 .

$$
W_{m e c}=\frac{1}{2} S_{33} v T^{2}
$$

\subsection{The electrical energy}

The electrical energy $W_{e l}$ is related to the coefficient $k_{33}$ and the mechanical strain, where the deformation is in the direction of the thickness [22] and is given by Equation 5 .

$$
W_{e l}=K_{33}^{2} W_{m e c}
$$

\subsection{Beam analysis}

This analysis is used to find the natural frequencies [18], which are given by Equation 6 .

$$
F_{n}=\frac{(\lambda)^{2}}{2 \pi L^{2}} \sqrt{\frac{E I}{m}}
$$


Table 4 First simulation based on the dimensions with steel

\begin{tabular}{llllllll}
\hline $\begin{array}{l}\text { Height } \\
\boldsymbol{h}(\mathbf{m})\end{array}$ & $\begin{array}{l}\text { Base } \\
\boldsymbol{b}(\mathrm{m})\end{array}$ & $\begin{array}{l}\text { Length } \\
\boldsymbol{L}(\mathbf{m})\end{array}$ & $\begin{array}{l}\text { Natural } \\
\text { frequency \#1 } \mathbf{1} \\
(\mathbf{H z})\end{array}$ & $\begin{array}{l}\text { Natural } \\
\text { frequency \#2 } \\
(\mathbf{H z})\end{array}$ & $\begin{array}{l}\text { Natural } \\
\text { frequency \#3 } \\
(\mathbf{H z})\end{array}$ & $\begin{array}{l}\text { Inertia } \\
\left(\mathbf{m}^{\mathbf{4}} \mathbf{l}\right.\end{array}$ & $\begin{array}{l}\text { Weight per } \\
\text { length }\left(\frac{\mathbf{k g}}{\mathbf{m}}\right)\end{array}$ \\
\hline 0.00063 & 0.041 & 0.041 & 7.79 & 48.84 & 136.77 & $8.54 \mathrm{E}-13$ & 322.26 \\
\hline
\end{tabular}

Table 5 First iteration of the beam dimensions using steel as material

\begin{tabular}{llllllll}
\hline $\begin{array}{l}\text { Height } \\
\boldsymbol{h} \mathbf{( m )}\end{array}$ & $\begin{array}{l}\text { Base } \\
\boldsymbol{b} \mathbf{( m )}\end{array}$ & $\begin{array}{l}\text { Length } \\
\boldsymbol{L} \mathbf{( m )}\end{array}$ & $\begin{array}{l}\text { Natural } \\
\text { frequency \# } \mathbf{1} \\
\mathbf{( H z )}\end{array}$ & $\begin{array}{l}\text { Natural } \\
\text { frequency \#2 } \\
\mathbf{( H z )}\end{array}$ & $\begin{array}{l}\text { Natural } \\
\text { frequency \#3 } \\
\mathbf{( H z )}\end{array}$ & $\begin{array}{l}\text { Inertia } \\
\left(\mathbf{m}^{\mathbf{4}} \mathbf{)}\right.\end{array}$ & $\begin{array}{l}\text { Weight per } \\
\text { length }\left(\frac{\mathbf{k g}}{\boldsymbol{m}} \mathbf{)}\right.\end{array}$ \\
\hline 0.00063 & 0.041 & 0.041 & 7.85 & 49.25 & 137.91 & 321.85 & $8.54327 \mathrm{E}-13$ \\
0.015 & 0.0254 & 0.08 & 135.13 & 846.90 & 2371.36 & 628 & $7.14375 \mathrm{E}-09$ \\
0.009 & 0.05 & 0.07 & 123.04 & 771.10 & 2159.10 & 549.5 & $3.0375 \mathrm{E}-09$ \\
\hline
\end{tabular}

Table 6 Second iteration of the beam dimensions using aluminum as material

\begin{tabular}{llllllll}
\hline $\begin{array}{l}\text { Height } \\
\boldsymbol{h}(\mathbf{m})\end{array}$ & $\begin{array}{l}\text { Base } \\
\boldsymbol{b}(\mathbf{m})\end{array}$ & $\begin{array}{l}\text { Length } \\
\boldsymbol{L}(\mathbf{m})\end{array}$ & $\begin{array}{l}\text { Natural } \\
\text { frequency \# } \mathbf{1} \\
(\mathbf{H z})\end{array}$ & $\begin{array}{l}\text { Natural } \\
\text { frequency \#2 } \\
(\mathbf{H z})\end{array}$ & $\begin{array}{l}\text { Natural } \\
\text { frequency \#3 } \\
(\mathbf{H z})\end{array}$ & $\begin{array}{l}\text { Inertia } \\
\left(\mathbf{m}^{\mathbf{4}} \mathbf{)}\right.\end{array}$ & $\begin{array}{l}\text { Weight per } \\
\text { length }\left(\frac{\boldsymbol{k g}}{\boldsymbol{m}} \mathbf{)}\right.\end{array}$ \\
\hline 0.00063 & 0.041 & 0.041 & 4.53 & 28.43 & 79.62 & 321.85 & $8.54327 \mathrm{E}-13$ \\
0.015 & 0.0254 & 0.08 & 78.02 & 488.96 & 1369.10 & 628 & $7.14375 \mathrm{E}-09$ \\
0.009 & 0.05 & 0.07 & 71.03 & 445.19 & 1246.55 & 549.5 & $3.0375 \mathrm{E}-09$ \\
\hline
\end{tabular}

Table $\mathbf{7}$ Third iteration of the beam dimensions using iron as material

\begin{tabular}{llllllll}
\hline $\begin{array}{l}\text { Height } \\
\boldsymbol{h}(\mathbf{m})\end{array}$ & $\begin{array}{l}\text { Base } \\
\boldsymbol{b} \mathbf{( m )}\end{array}$ & $\begin{array}{l}\text { Length } \\
\boldsymbol{L} \mathbf{( m )}\end{array}$ & $\begin{array}{l}\text { Natural } \\
\text { frequency \# } \mathbf{1} \\
\mathbf{( H z )}\end{array}$ & $\begin{array}{l}\text { Natural } \\
\text { frequency \#2 } \\
(\mathbf{H z})\end{array}$ & $\begin{array}{l}\text { Natural } \\
\text { frequency \#3 } \\
(\mathbf{H z})\end{array}$ & $\begin{array}{l}\text { Inertia } \\
\left(\mathbf{m}^{\mathbf{4}} \mathbf{)}\right.\end{array}$ & $\begin{array}{l}\text { Weight per } \\
\text { length }\left(\frac{\boldsymbol{k g}}{\boldsymbol{m}} \mathbf{)}\right.\end{array}$ \\
\hline 0.00063 & 0.041 & 0.041 & 5.33 & 33.43 & 93.61 & 322.67 & $8.54327 \mathrm{E}-13$ \\
0.015 & 0.0254 & 0.08 & 91.72 & 574.85 & 1609.61 & 629.6 & $7.14375 \mathrm{E}-09$ \\
0.009 & 0.05 & 0.07 & 83.51 & 523.40 & 1465.53 & 550.9 & $3.0375 \mathrm{E}-09$ \\
\hline
\end{tabular}

Where: $\lambda$ is the flexural mode, $L$ is the length of the beam in $\mathrm{m}, E$ is the modulus of elasticity of the beam, in $\mathrm{N} / \mathrm{m}^{2}$, $I$ the moment of inertia of the cross section of the beam with respect to its neutral axis in $\mathrm{m}^{4}, m$ is the mass per unit length of the beam in $\mathrm{kg} / \mathrm{m}$. Before calculating the natural frequency, inertia at the neutral axis in Equation 7 , and mass per unit length of the beam in Equation 8 must be found [18].

$$
I=\frac{1}{12} b h^{3}
$$

where $I$ is the moment of inertia of the cross section of the beam with respect to its neutral axis in $\mathrm{m}^{4}, b$ is the base of the beam, and $h$ is the height of the beam [18].

$$
m=d L
$$

(8) Since the natural frequencies do not match in the Where $d$ is the material density, $L$ is the length of the beam.

\section{Analysis and results}

\subsection{Analysis and results of the cantilever beam}

The iterations to match the cantilever beam and the piezo frequencies are shown in Table 4. Their natural frequencies were obtained using Equations 6, 7 and 8. In the research carried out by [9], it was shown that when the piezoelectric material and the cantilever beam have the same frequency, they resonate thereby increasing the power generated. The natural frequency of the piezo is 2.2 $\mathrm{kHz}$. first iteration, a new iteration is performed. Tables 5,6 , and 7 were conducted with three boundary conditions for three different dimensions. Iterations are performed until the three frequencies of the beam are in the range of the piezo natural frequency. From the results, the material selected is steel, since the frequencies in two of the three 
iterations are within the following range: from 1.9 to 2.5 $\mathrm{kHz}$.

Once the iterations are performed and the material of the beam is selected, the beam dimensions will be assessed by a simulation to find its dynamic characteristics. Figure 5 a shows the beam supporting 67.99 MPa and having a maximum displacement is $0.073 \mathrm{~mm}$ (Figure 5b). The above data are key in determining the cross section of the tile and its resistance to the desired load.

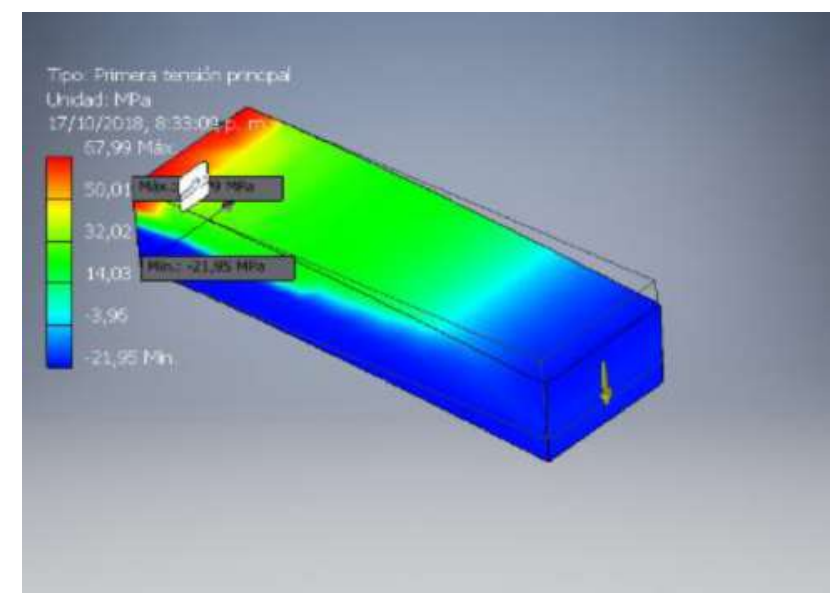

(a)

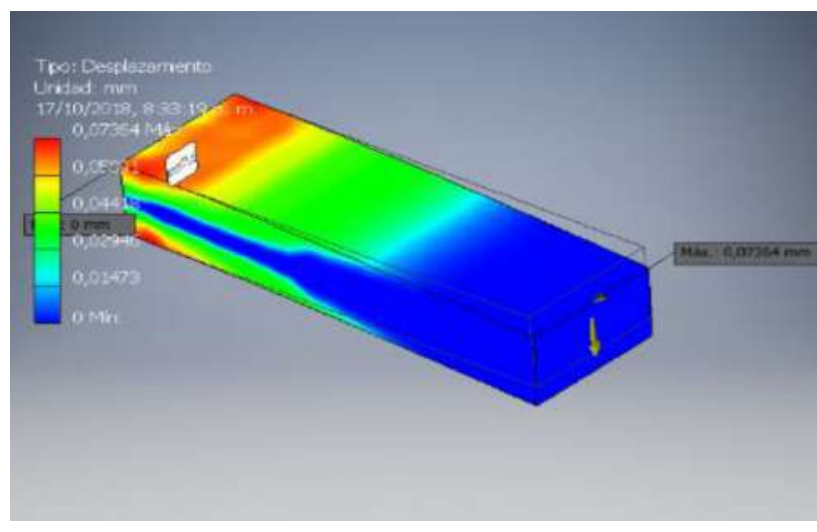

(b)

Figure 5 Finite Element Analysis of the cantilever beam obtained in the first iteration: a) stress results, and b] displacement results

The second configuration can withstand more than 16.24 $\mathrm{MPa}$ (principal stress 84.23 $\mathrm{MPa}$ as shown in Figure $6 a$ and have a maximum displacement of $0.1198 \mathrm{~mm}$ (Figure 6b), higher than the first simulation $(0.073 \mathrm{~mm}$ ). The dimensions of the beam were: $0.009 \mathrm{~m}$ height, 0.05 $\mathrm{m}$ wide, and $0.07 \mathrm{~m}$ long; suitable for the resonance frequency of the piezoelectric material as shown in Table 5. It is necessary to perform the simulation of the beam to obtain the maximum displacement and stress (Figure 6).

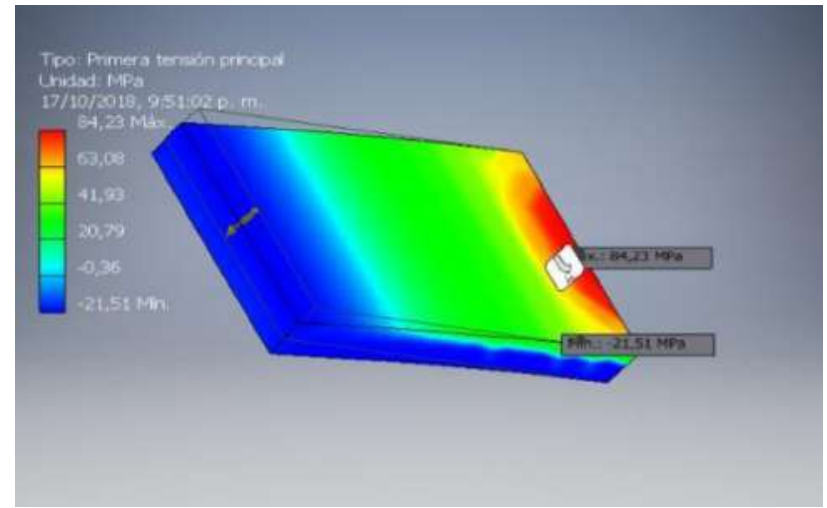

(a) Stress analysis

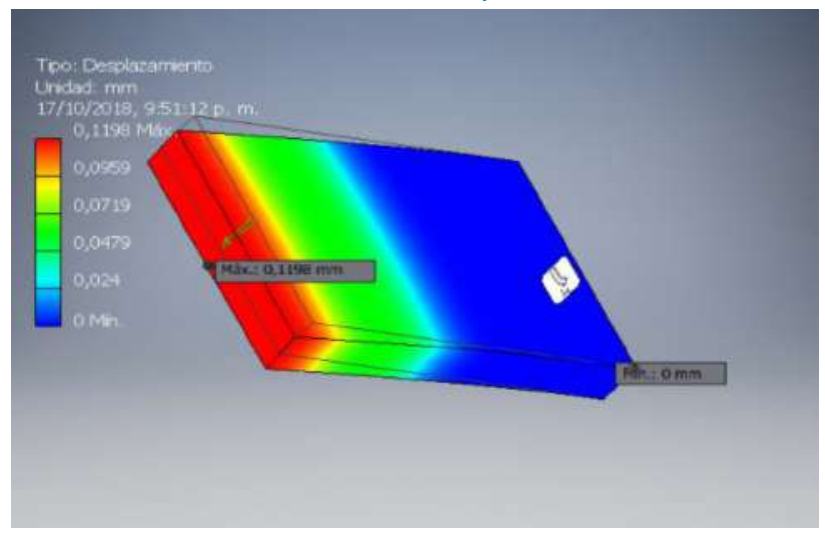

(b) Displacement analysis

Figure 6 Finite element analysis of the cantilever beam obtained in the second iteration: al stress results, and b) displacement results

\subsection{Analysis of power generation}

It was decided to store the energy in ultracapacitors because they can store more energy for short periods of time. Additionally, special care should be taken when storing the maximum amount of power to avoid the sudden discharge of the ultracapacitor. In order to perform a mathematical analysis of the voltage generated, an average weight from 5 to $80 \mathrm{~kg}$ is applied to the piezoelectric. The voltage generated ranges between -1 and $-14 \mathrm{~V}$ (Table 8, and Figure 7). Deforming the piezoceramic in length (i.e., flexural moment), the index of the piezoelectric constant coupling factor $k_{31}$ is used instead of the index $k_{33}$, Equation 2 according to [22]. To find the field strength, the spring constant and the electric power applied Equations 3-5. The values for the graph were: Piezoelectric area $0.025 \mathrm{~m}$, thickness $0.00063 \mathrm{~m}$, piezoelectric constant $g_{33} 14 \mathrm{Vm} / \mathrm{N}$, Piezoelectric charge constant $d_{33} 603 \mathrm{C} / \mathrm{N}$, electromechanical coupling factor $k_{33}$ $68 \%$ and $k_{31} 36 \%$ average time in seconds per step 0.52 s. 
Table 8 Voltage generated according to piezoelectric stress

\begin{tabular}{lllllll}
\hline $\begin{array}{l}\text { Applied } \\
\text { weight }(\mathbf{k g})\end{array}$ & Force (N) & Stress (Pa) & $\begin{array}{l}\text { Voltage } \\
\text { generated } \\
\text { (V) }\end{array}$ & $\begin{array}{l}\text { Field } \\
\text { strength } \mathbf{V} / \mathbf{m})\end{array}$ & $\begin{array}{l}\text { Elasticity } \\
\text { constant }\end{array}$ & $\begin{array}{l}\text { Electrical } \\
\text { energy }\left(\mathbf{W}_{\text {el }}\right)\end{array}$ \\
\hline 5 & 49.05 & 99923 & -1 & -1398.93 & $-8.43557 \mathrm{E}-07$ & 0,68 \\
10 & 98.1 & 199847 & -2 & -2797.86 & $-1.68711 \mathrm{E}-06$ & 2.75 \\
15 & 147.15 & 299771 & -3 & -4196.80 & $-2.530 \mathrm{E}-06$ & 6.19 \\
20 & 196.2 & 399695 & -4 & -5595.73 & $-3.374 \mathrm{E}-06$ & 11.02 \\
25 & 245.25 & 499619 & -4 & -6994.66 & $-4.21 \mathrm{E}-06$ & 17.21 \\
30 & 294.3 & 599543 & -5 & -8393.60 & $-5.061 \mathrm{E}-06$ & 24.79 \\
35 & 343.35 & 699466 & -6 & -9792.53 & $-5.90 \mathrm{E}-06$ & 33.74 \\
40 & 392.4 & 799390 & -7 & -11191.47 & $-6.74 \mathrm{E}-06$ & 44.08 \\
45 & 441.45 & 899314 & -8 & -12590.40 & $-7.591 \mathrm{E}-06$ & 55.79 \\
50 & 490.5 & 999238 & -9 & -13989.33 & $-8.43 \mathrm{E}-06$ & 68.87 \\
55 & 539.55 & 1099162 & -10 & -15388.27 & $-9.27 \mathrm{E}-06$ & 83.34 \\
60 & 588.6 & 1199086 & -11 & -16787.20 & $-1.01 \mathrm{E}-05$ & 99.18 \\
65 & 637.65 & 1299009 & -11 & -18186.13 & $-1.09 \mathrm{E}-05$ & 116.40 \\
70 & 686.7 & 1398933 & -12 & -19585.07 & $-1.18 \mathrm{E}-05$ & 134.99 \\
75 & 735.75 & 1498857 & -13 & -20984.006 & $-1.26 \mathrm{E}-05$ & 154.97 \\
80 & 784.8 & 1598781 & -14 & -22382.94 & $-1.34 \mathrm{E}-05$ & 176.32 \\
\hline
\end{tabular}

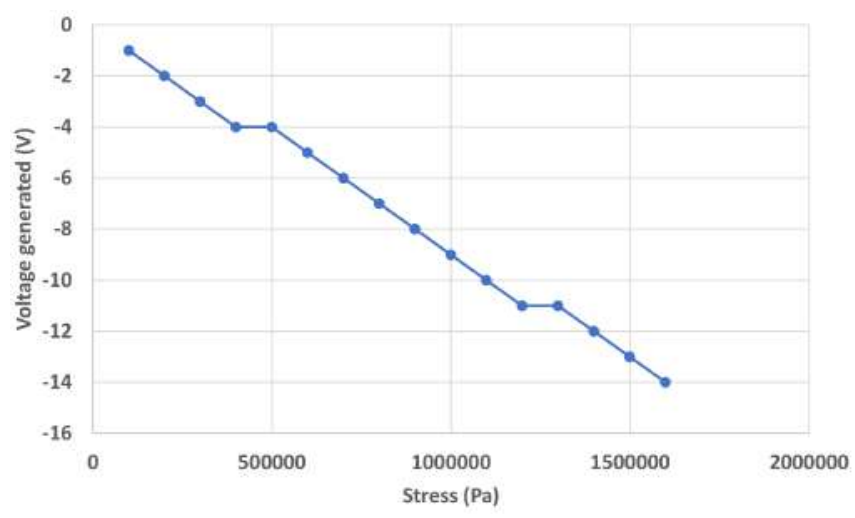

Figure 7 Voltage generated according to the applied stress

The electric power generated should be stored. Impedances and piezo electronic networks must match as suggested by the manufacturer [22].

Figure 8 shows the voltage generated by a Buzzer type piezo when its frequency matches the one of the cantilever beam. The test was performed with the piezoelectric to verify the output voltage when it was subjected to high oscillation frequencies. This type of piezo is not made for generation because its very low output current, and its high impedance. A maximum power of $375 \mathrm{~mW}$ was obtained with a voltage of $25 \mathrm{~V}$, recalling that the piezoelectric generates an output signal in alternating current $(A C)$. The vibration period of the cantilever beam is $238 \mathrm{~ms}$, as can be seen in the oscilloscope (Figure 8). The decay ratio of the vibrations is $76.63 \%$. The actual module with the circuit in which the test was performed is shown in Figure 9. This is: a) the cantilever beam which was simulated by a saw blade, b) the piezoelectric material Buzzer type, and c) servomotor which simulated a mechanical load on the end of the cantilever beam.

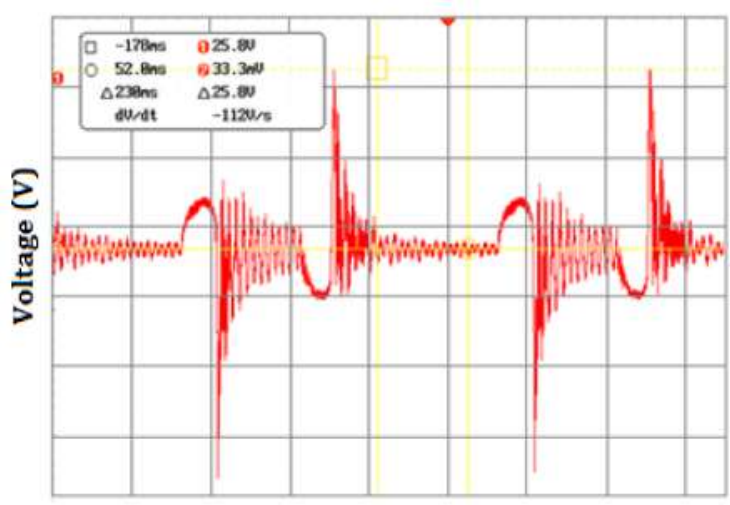

Time (ms)

Figure 8 Voltage generated by the piezoelectric unground observed from the oscilloscope

\subsection{Energy analysis when pedestrians step in the tile}

An $80 \mathrm{~kg}$ pedestrian stepping in the energy harvester will produce $510 \mathrm{E}-3 \mathrm{~J}$, as shown in Figure 10. The power generation process is an open loop system, because the output does not provide a feedback to the input (Figure 11). This is done in order to rectify the signals from the piezo. Additionally, a capacitor is used to store the energy generated (Figure 12). 


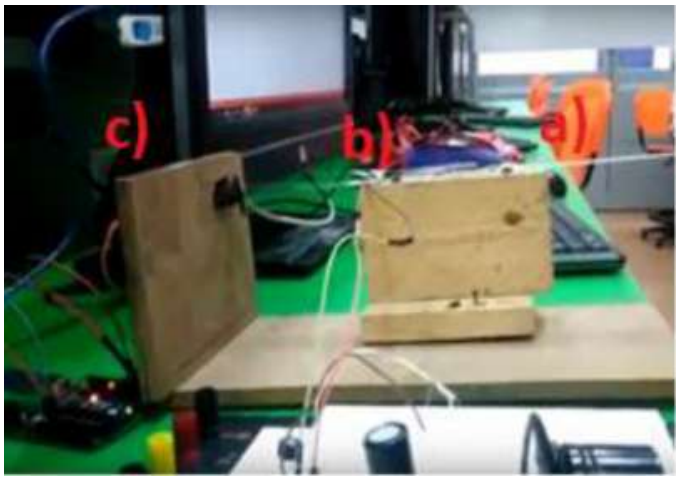

Figure 9 Operation piezoelectric beam load simulating a servomotor, $\mathrm{c}$ is the servomotor $\mathrm{b}$ is the cantilever beam, where: a) the cantilever beam, b) the piezoelectric material Buzzer type, and c) servomotor which simulated a mechanical load on the end of the cantilever beam

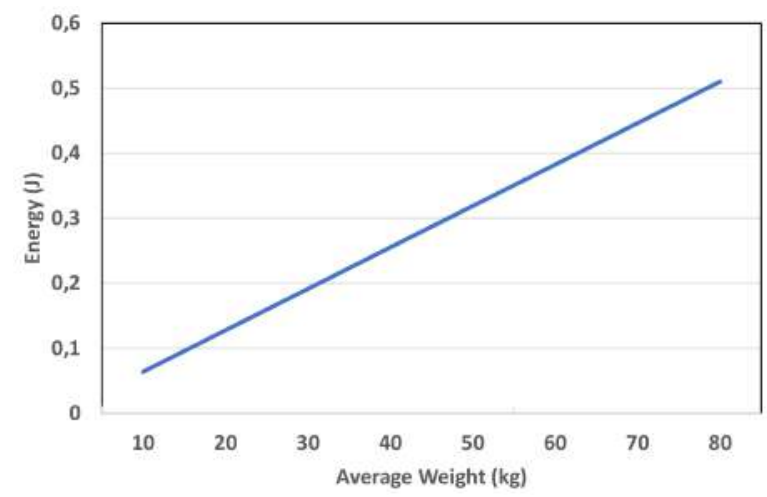

Figure 10 Potential energy generated by the weight in kg

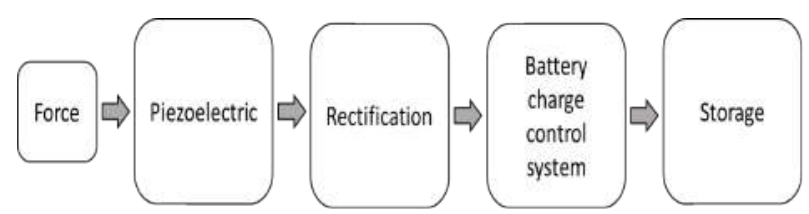

Figure 11 Process block open storage of energy produced by the piezo

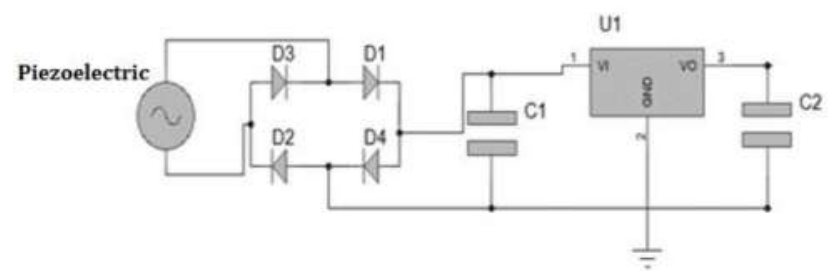

Figure 12 Proposed energy storage circuit

Before the use of the beam, an output voltage of only 5 $\checkmark$ was generated by the piezo. When the cantilever beam was used, an output voltage of $25 \mathrm{~V}$ was obtained with the same deformation. This means an increase of $500 \%$ due to the use of the cantilever beam, which translates into an increase of $500 \%$ in the energy generated.

\section{Conclusions}

The voltage generated is greatly improved by the use of a cantilever beam designed to resonate with the natural frequency of the piezoelectric. The maximum voltage reached by the beam was 25 VAC, peak to peak voltage.

The selection of the material for the cantilever beam is a decisive factor, since the Young's modulus is one of the most influential parameters in the natural frequency of the beam. The implementation of a cantilever beam should ensure optimization of space, safety, and quality.

Buzzer-type piezoelectric devices have a high impedance, which means having a high resistivity to the current. Other piezoelectric materials that are designed for CEP should have better performance.

The high impedance of the piezoelectric current tends to be very low, so it takes longer to charge the capacitor. Therefore, ultracapacitors are recommended for this application since charge moves much faster than within lithium ion batteries. Thereby allowing more energy harvesting and avoiding lost of ions. Future work will consist in discussing the charging period and the efficiency obtained with the circuit, with their improvements, bearing in mind that to make this system an effective solution engineers and researchers must work hard in the manufacture of low energy equipment and very efficient use of this resource.

It would be appropriate to use preferably organic piezoelectric materials or materials that do not jeopardize the health or the environment.

\section{Declaration of competing interest}

None declared under financial, profesional and personal competing interests.

\section{Acknowledgements}

We would like to express our deepest appreciation to all those who provided the possibility to complete this paper and special thanks and gratitude to our professors: Jose Alejandro Posada-Montoya, Jose Alfredo Palacio, and Edison Garcés Zapata, for the opportunity to do this project and made it possible. Secondly, we would also like to say thanks to our parents who helped us a lot in finalizing this project, for supporting us in everything. Thanks to Institución Universitaria Pascual 
Bravo, Sapiencia, Facultad de Ingeniería, Semillero de Investigación Ambiental, Grupo de Investigación e Innovación Ambiental, Expotecnologica, and Dirección de Tecnología e Innovación.

\section{References}

[1] M. Allen and et al., "IPCC special report on the impacts of global warming of $1.5^{\circ} \mathrm{C}$ - summary for policy makers," IPCC, Tech. Rep., Oct. 2018.

[2] V. Masson and et al., "Global warming of $1.5^{\circ} \mathrm{C}$ : An IPCC special report on the impacts of global warming of $1.5^{\circ} \mathrm{C}$ above pre-industrial levels and related global greenhouse gas emission pathways, in the context of strengthening the global response to the threat of climate change," IPCC, Tech. Rep., 2018.

[3] O. Edenhofer and et al., "AR5 climate change 2014: Mitigation of climate change," IPCC, New York, USA, Tech. Rep., 2014.

[4] T. Kaberger, "Progress of renewable electricity replacing fossil fuels," Global Energy Interconnection, vol. 1, no. 1, January 2018. [Online]. Available: https://doi.org/10.14171/j.2096-5117.gei.2018. 01.006

[5] S. Kim, J. Shen, and M. Ahad, "Piezoelectric-based energy harvesting technology for roadway sustainability," International Journal of Applied Science and Technology, vol. 5, no. 1, pp. 20-25, Feb. 2015.

[6] L. Li, "Rectifying the output of vibrational piezoelectric energy harvester using quantum dots," Sci Rep, vol. 7, March 202017. [Online]. Available: https://doi.org/10.1038/srep44859

[7] F. J. Agatón. (2014, May 22) Análisis de la factibilidad económica y ambiental de utilizar baldosas piezoeléctricas en el campus de la Universidad Militar Nueva Granada (UMNG). [Online]. Available: https://bit.ly/20SCULc

[8] P. V. Avvari, Y. Yang, and C. K. Soh, “Long-term fatigue behavior of a cantilever piezoelectric energy harvester," J. Intell. Mater. Syst. Struct., vol. 28, no. 9, 2017. [Online]. Available: https: //doi.org/10.1177/1045389X16667552

[9] N. Chen, H. J. Jung, H. Jabbar, T. H. Sung, and T. Wei, “A piezoelectric impact-induced vibration cantilever energy harvester from speed bump with a low-power power management circuit," Sensors Actuators A Phys., vol. 254, February 01 2017. [Online]. Available: https://doi.org/10.1016/j.sna.2016.12.006
[10] H. Ghasemzadeh, "Interleaved piezoelectric tactile interface," U.S. Patent 9383 848B2, Jul. 05, 2016.

[11] J. Rodel and et al., "Transferring lead-free piezoelectric ceramics into application," Journal of the European Ceramic Society, vol. 35, no. 6, June 2015. [Online]. Available: https://doi.org/10.1016/j. jeurceramsoc.2014.12.013

[12] Y. M. You and et al., "An organic-inorganic perovskite ferroelectric with large piezoelectric response," Science, vol. 357, no. 6348, July 21 2017. [Online]. Available: https://doi.org/10.1126/science. aai8535

[13] P. Skladal, "Piezoelectric biosensors," TrAC Trends in Analytical Chemistry, vol. 79, December 2015. [Online]. Available: https: //doi.org/10.1016/j.trac.2015.12.009

[14] D. A. Valle, A. F. Castaño, J. Gallego, and A. M. Hernandez, "Test and fabrication of piezoresistive sensors for contact pressure measurement," Revista Facultad de Ingeniería Universidad de Antioquia, no. 82, March 2017. [Online]. Available: https://doi.org/10.17533/udea.redin.n82a06

[15] E. F. Forero, O. M. Gelvez, and C. A. Torres, "Piezoelectric transducer design for electric power generation," Revista UIS Ingenierías, vol. 18, no. 1, June 22 2019. [Online]. Available: https://doi.org/10.18273/revuin.v18n1-2019010

[16] Piezoelectric sound components. murata. Accessed Oct. 16, 2018. [Online]. Available: https://bit.ly/2KUTvNL

[17] Herramienta de corte ficha técnica. Servimezclas center. Accessed Oct. 21, 2018. [Online]. Available: https://bit.ly/20PogEn

[18] L. A. Bedian, “Determinación experimental de los parámetros modales (frecuencias naturales) de una viga en condición empotrada - libre," M.S. thesis, Universidad Verecruzana, Boca del Rio, México, 2010.

[19] (2003) LM 7805 data sheet. Texas instruments. Accessed Oct. 21, 2018. [Online]. Available: https://bit.ly/34rZf92

[20] Digital Storage Oscilloscope, Gwinstek, Taiwan, China, 2013.

[21] J. Nilsson and A. Thorstensson, "Ground reaction forces at different speeds of human walking and running," Acta Physiol. Scand., vol. 136, no. 2, pp. 217-227, Jun. 1989.

[22] Energy harvesting. Johnson Matthey. Accessed May. 07, 2017. [Online]. Available: https://bit.ly/20o2oRw

[23] A. F. González and R. M. Cesari. (2009) Materiales piezoeléctricos y efecto piezoeléctrico. Univ. Tecnológica Nac. Buenos Aires, Argentina. [Online]. Available: https://bit.ly/34yCHDA 